\title{
O Crescimento das Áreas Metropolitanas \\ e a Descentralização
}

\author{
LEO F. SCHNORE \\ Tradução de MARY CARDoso
}

\section{INTRODUÇÃo}

\begin{abstract}
A
atual literatura sôbre descentralização, existente nos Estados Unidos, ressente-se de falta de perspectiva histórica e, em conseqüência, as hipóteses comprováveis e expressas em têrmos dinâmicos são extremamente raras. Do ponto de vista histórico, a descentralização foi uma decorrência do progresso tecnológico, de modo particular das novas facilidades de deslocamento de sêres humanos, das comodidades que se foram tornando disponíveis e das posssibilidades de informação. Os centros urbanos estão adotando um novo padrão, no que concerne às relações espaciais, mas a perfeita compreensão do processo requer pesquisas mais profundas, que permitam a verificação das hipóteses dinâmicas. $\mathrm{E}$ as maiores deficiências encontram-se no estudo empírico e inadequado de transportes e comunicações.
\end{abstract}

$$
\because \quad * \quad *
$$

Nos últimos anos, muito esfôrço tem-se dedicado à pesquisa sôbre o crescimento das cidades e a descentralização, e os minuciosos estudos estatísticos de THOMPSON, Bogue e HAwley, muito especialmente, permitiram uma clara visão dos principais fatos demográficos. Não obstante, uma busca na documentação disponivel revela duas importantes omissões: não há, em parte alguma, sucinta recapitulação histórica, que ofereça descrição sumária do desenvolvimento metropolitano, de seus primórdios até o nosso tempo. $\mathrm{E}$, provàvelmente em conseqüência dessa lacuna, contém a literatura existente pouquíssimas hipóteses tipicamente de desenvolvimento, ilustrativas do crescimento das metrópoles e da descentralização. O presente trabalho diz respeito, assim, a êsses dois grandes problemas e oferecemos, primeiro, um ligeiro estudo descritivo do crescimento e do desenvolvimento das áreas metropolitanas. Em seguida apresentamos, sob a forma de problemas concretos, para pesquisa, uma série de conclusões, derivada da resenha inicial. Em cada problema a ênfase é posta sôbre o processo, num esfôrço franco para sobrepujar a orientação estatística da literatura existente. Muitas das hipóteses, além disso, referem-se, de modo específico, a influência dos transportes, fator freqüentemente mencionado, mas raramente estudado, na tessi- 
tura do problema metropolitano. O aspecto histórico é, deliberadamente, expresso em têrmos muito gerais e a maior parte das afirmações é muito bem fundamentada, embora diversa em sua origem. Outras repousam em provas mais limitadas e algumas poucas, ainda que francamente especulativas, são apresentadas como questões para pesquisa de ordem prática e não como respostas definitivas.

\section{MEIO SÉCULO DE CRESCIMENTO METROPOLITANO}

O crescimento metropolitano pode ser melhor concebido como uma nova forma de desenvolvimento urbano, fenômeno característico da América do século XX. (2) E' de ser reconhecida, naturalmente, a ocorrência de grande aumento das populações urbanas antes dêste século, pois desde 1820 que as cidades se vêm desenvolvendo mais ràpidamente que as zonas rurais . Contudo, a primeira década do século $\mathrm{XX}$ marcou o fim de uma fase importante do desenvolvimento urbano, sendo a última em que as migrações de outros países contribuíram, com grandes contingentes, para o crescimento das cidades americanas. A década de 1910 a 1920, incluindo, como o fêz, a primeira guerra mundial, testemunhou o surgimento de grandes correntes migratórias do exterior e, como conseqüência, o retardamento do ritmo do crescimento urbano. (3) As leis restritivas vigentes na década de 1920, impondo rígido sistema de cotas, impediram que a migração internacional voltasse à escala de antes da guerra, mas a população nacional continuou a aumentar e as cidades a crescerem ràpidamente, agora, porém, graças principalmente às migrações internas. O crescimento mais atenuado das cidades, no período de 1930-1940 foi, também, o resultado de um declínio do movimento migratório, mas nesse caso consistindo num fluxo mais reduzido de migração interna, isto é, da população rural para a zona urbana. As oportunidades de emprêgo nas áreas urbanas, dràsticamente reduzidas durante a depressão, multiplicaram-se nos primeiros anos da década de 1940 , graças sobretudo às exigências de tempo de guerra. Tais oportunidades mantiveram-

(1) Tanto a narrativa de caráter histórico, quanto o conseqüente esbôço de problemas para pesquisa, se baseiam no pressuposto de que o quadro seral do desenvolvimento metropolitano deveria ser estabelecido antes que se examinassem, em minúcia, as variações de caráter individual. Não visa essa orientação. a desacreditar o sistema de estudo de casos de áreas específicas, fonte de pesquisas extremamente importante, embora um excessivo interêsse pelos casos excepcionais nos pareça, a esta altura, algo prematuro. A documentação sôbre as tendências principais afigura-se-nos critério muito mais proveitoso, pois uma vez firmemente estabelecida a ampla trama das relações, as execuções definem-se como variações das tendências centrais, por si mesmas explicáveis.

(2) Veja-se Introdução à História Econômica, de Gras, N.S.B., Harper \& Bros., 1922 e A Comunidade Metropolitana, de MCKenzIE, R. D., McGraw-Hill Book Co., 1933, Nova York.

(3) O crescimento natural não era, aparentemente, fator de compensação de importância alguma, durante o período considerado, uma vez que os habitantes das cidades não se reproduziam em níveis de substituição. Há, contudo, prova de que êsse fato, de há muito comprovado, deixou de ter influência na última década decorrida entre os censos. (Veja-se Componentes das variações populacionais nas áreas urbanas e suburbanas das zonas metropolitanas tipicas, de 1940 a 1950 , de BOGUE, D. J. e SEIM, E., in "Sociologia Rural", n. ${ }^{\circ}$ XXI, set./dez, de 1956, pp. 265 a 275). 
se em nível bastante elevado nos anos imediatamente subseqüentes à segunda guerra mundial, quando a nação retornava a uma economia de paz, e foram ainda estimuladas ao irromperem as hostilidades na Coréia.

TABELA 1 (*)

TAXAS DE AUMENTO POPULACIONAL, DE 1900 A 1950, SEGUNDO STATUS METROPOLITANO

$\begin{array}{ccccccc} & & 1940 & 1930 & 1920 & 1910 & 1900 \\ \text { Status Metropolitano. . . . . . . } & 50 & 40 & 30 & 20 & 10\end{array}$

\section{A. TAXAS DE AUMENTO DE POPULAÇÃo ENTRE AS DÉCADAS}

\begin{tabular}{|c|c|c|c|c|c|}
\hline Total nos Estados Unidos....... & 14,5 & 7,2 & 16,1 & 14,9 & 21,0 \\
\hline Zona não metropolitana........ & 6,1 & 8,5 & 6,0 & 6,7 & 13,6 \\
\hline Zona metropolitana. . . & 22,0 & 8,4 & 27,5 & 25,9 & 32,5 \\
\hline Cidades centrais. $\ldots \ldots \ldots \ldots$ & 13,8 & 5,5 & 24,2 & 27,9 & 37,1 \\
\hline Círculos. . . & 34,2 & 13,4 & 33,2 & 22,4 & 25,6 \\
\hline Urbanos. . . . & 26,0 & 8,0 & 42,6 & 35,9 & 49,2 \\
\hline Rurais. $\quad \ldots \ldots \ldots \ldots \ldots \ldots$ & 45,2 & 21,3 & 22,0 & 9,4 & 8,4 \\
\hline Zona incorporada. . . . . . . & 34,1 & 13,2 & 28,6 & 24,1 & 45,0 \\
\hline Zona não incorporada. & 46.5 & 22.3 & 21,2 & 7.8 & 5.6 \\
\hline
\end{tabular}

\section{B. PROPORÇÃO DO AUMENTO TOTAL EM TODO O PAÍS}

\begin{tabular}{|c|c|c|c|c|c|}
\hline Zona não metropolitana. & 0,43 & 1,18 & 0,37 & 0,45 & 0,65 \\
\hline Zona metropolitana. . . ........ & 1,52 & 1,17 & 1,71 & 1,74 & 1,55 \\
\hline Cidades centrais. . ... & 0,95 & 0,76 & 1,50 & 1,87 & 1,77 \\
\hline Círculos. . . $\ldots \ldots \ldots \ldots$ & 2,36 & 1,86 & 2,06 & 1,50 & 1,22 \\
\hline Urbanos. . $\ldots \ldots \ldots \ldots \ldots \ldots$ & 1,79 & 1,11 & 2,65 & 2,41 & 2,34 \\
\hline Rurais. . $\ldots \ldots \ldots \ldots \ldots \ldots$ & 3,12 & 2,96 & 1,37 & 0,63 & 0,40 \\
\hline Zona incorporada. . . . . . . & 2,35 & 1.83 & 1,78 & 1,62 & 2,14 \\
\hline Zona não incorporada. . & 3,21 & 3,10 & 1,32 & 0,52 & 0,27 \\
\hline
\end{tabular}

Quais foram os concomitantes metropolitanos do crescimento urbano, no século XX? A primeira parte da Tabela 1 mostra as taxas de aumento dentro de tôda a zona continental dos Estados Unidos, durante as décadas consideradas. Nessa tabela, o total de área terrestre nacional está representado de acôrdo com o status metropolitano, sendo a primeira distinção feita entre as zonas metropolitanas e as não metropolitanas. A subdivisão seguinte diz respeito aos núcleos metropolitanos e aos "círculos" que os rodeiam. As taxas de crescimento das zonas urbanas e rurais de cada círculo são mostradas separadamente e por último figuram, dentro da porção "rural" do círculo, taxas distintas de crescimento das áreas incorporadas e das não incorporadas. A parte $b$ mostra tôdas essas taxas como proporções do aumento verificado em todo o país, oferecendo elementos para o contrôle da variação havida no crescimento total, no espaço de tempo compreendido entre as décadas. (4)

(*) Fonte - Padrões de descentralizações, por Schnore, L. F., tese de doutorado, não publicada, apresentada em 1955 à Universidade de Michigan, tabela 101, p. 214.

(4) As definições oficiais das 168 áreas metropolitanas típicas, reconhecidas pelo Bureau do Censo, retrocederam a 1900, de modo que área é, aí, uma constante. A "velha" definição de urbano, do recenseamento de 1940 , é amplamente usada. Graças a diferença na conceituação das áreas, as taxas indicadas não coincidem exatamente com as 
A Tabela 1 mostra que as áreas, atualmente definidas como metropolitanas, absorveram parcela desproporcionalmente grande do total do aumento de população verificado no país, em todo o período de cinqüenta anos considerado. Dentro das áreas metropolitanas, porém, o crescimento das cidades centrais, isto é, dos núcleos citadinos, foi sendo progressivamente menor, enquanto que os círculos mostraram a tendência ao crescimento cada vez mais rápido. A essa constante de diferente crescimento, favorável à zona periférica, costuma-se, geralmente, denominar "descentralização", embora tais percentagens reflitam, apenas, mudanças "liquidas", decorrentes de uma profusão de causas.

O ritmo vagaroso do crescimento citadino resulta, em parte, da incapacidade ou da inabilidade das cidades para absorção das áreas circunvizinhas, dennsamente povoadas. Talvez mais significativas, ainda, sejam duas tendências complementares da migração e da flutuação residencial: a que têm os habitantes do centro de se deslocar, cada vez em maior número, para várias

- partes do círculo adjacente, e o movimento das migrações do interior diretamente para o círculo, e não para a cidade pròpriamente dita. A consequiência final é uma relativa descentralização, ou crescimento líquido periférico, maior do que o do centro. Do ponto de vista da migração e da mobilidade, a descentralização tem duas origens: re-locação, do centro para fora, e aumento, por acrescentamento, da periferia. A importância relativa dêsses dois tipos distintos de deslocamento, contudo, não foi ainda firmemente definida. (5)

Entretanto, apesar de nossas inadequadas respostas a essas questões fundamentais, recentes estudos estabeleceram algumas relações importantes entre o grau de descentralização e certas características, estruturais e funcionais, das áreas metropolitanas. Uma das maneiras de definí-las consiste em minimizar, deliberadamente, a importância do desenvolvimento metropolitano, como processo mais ou menos contínuo, e apresentar as conclusões das pesquisas mais recentes em sua seqüência histórica.

No comêço do século, muitos centros urbanos eram ainda entidades bastante compactas e confinadas. A maior parte das grandes cidades situa-

que figuram no trabalho "Aumento de população nas áreas metropolitanas típicas de 1900 a 1950", de BOGUE, D. J., Imprensa Oficial, 1953. Os dados de Bogue, constantes da Tabela 1, dizem respeito a 162 áreas metropolitanas com áreas equivalentes a condados, usadas na Nova Inglaterra, em lugar das áreas com base em vilas, definidas pelo Bureau do Censo. Uma vez que empregamos neste trabalho as definições oficiais das áreas metropolitanas típicas, os dados não são diretamente comparáveis com os que se encontram na obra de THOMPSON, W. S., "Crescimento dos Distritos Metropolitanos nos Estados Unidos da América, de 1900 a 1940”, Imprensa Oficial, 1947, Washington.

(5) A importância comparativa dessas duas correntes migratórias só é conhecida em relação a poucas áreas, e a um período de tempo limitado e, provàvelmente, atípico. Os dados sôbre migrações, apurados pelo recenseamento de 1940 podem ser examinados em função dos locais de residência dos migrantes que em 1935 viviam nos núcleos metropolitanos e em 1940 nos círculos adjacentes. (Veja-se em "Ohio, de 1935 a 1940", de THOMPSON, W. S., publicação da Fundação Scripps para pesquisa de problemas populacionais, 1951, Oxford, Oȟio, e "Migração Interestadual em Michigan, de 1935 a 1940", de HAWLEY, A. H., publicação do Instituto de Administração Pública, da Universidade de Michigan, 1953, Ann Arbor). 
va-se à beira-mar, embora algumas começassem a desenvolver-se no İnterior, em entroncamentos ferroviários. Seus habitantes concentravam-se perto dos principais locais de trabalho, em alojamentos ou casas enfileiradas, a maioria tendo que andar a pé até o lugar de trabalho, ou que viajar em veículos públicos. Os carros puxados a cavalo eram ainda muito vistos nas ruas, embora já começassem a ser substituídos pelos carros elétricos. O automóvel, porém, era ainda uma novidade, e seu preço estava apenas nas possibilidades dos ricos. Dentre êsses, muitos que podiam dispor do tempo e do dinheiro para a viagem, passavam a morar fora da cidade congestionada, vindo para o trabalho de automóvel ou de trem interurbano. (6)

Esses trens, movidos a vapor ou a eletricidade, partiam das grandes cidades e irradiavam-se, em compridas fieiras, ao longo das quais começaram a aparecer aglomerados humanos, tendo entre uns e outros enormes áreas de campo aberto, quase todo constituído de fazendas. Pequenos vilarejos, espalhados por tôda essa extensão e localizados nas interseções das estradas rurais, atendiam às necessidades mais urgentes da população campesina, fazendo-se através dêles a distribuição dos produtos manufaturados exigidos pelas atividades agrícolas. Tais lugarejos serviram, também, como ponto de convergência para a produção agrícola do interior.

Os subcentros urbanos de maior tamanho, dentro da órbita das cidades centrais, forneciam ao inteiro os produtos de necessidade menos imediata. Além de servirem como pontos de convergência e distribuição, êsses aglomerados maiores eram também, com frequiência, produtores de utilidades, de modo especial quando havia fôrça hidráulica, próxima $\epsilon$ disponível. Não obstante, a maior parte das indústrias concentrava-se ainda na cidade grande, onde era possível fazer-se maior economia de energia. Os subcentros maiores dispunham, via de regra, de serviço direto de trens para o centro da cidade e sôbre êsses trilhos deslizava a tremenda massa da carga interurbana. Enfim, o conjunto composto pela cidade e os vilarejos aglomerados podia ser comparado a um planêta e seus satélites.

As cidades maiores cresciam ainda mais ràpidamente que os lugarejos, principalmente graças às migrações, e a população rural reduzia-se continuamente, na proporção em que iam sendo empregados novos e mais eficientes métodos agrícolas e em que as pequenas granjas se iam fundindo em organizações maiores. O excedente da população agrícola fluía para a cidade, provàvelmente numa série de deslocamentos intermitentes, e a êle se juntavam, mais tarde, os imigrantes estrangeiros. (8)

Nos primeiros anos do século, as áreas metropolitanas eram, por isso, caracterizadas por uma disposição populacional em forma de estrêla, ou

(6) In Crescimento das cidades no século 19, de Weber, A. F., Imprensa da Univ. de Columbia, 1899, New York.

(7) Veja-se Nossas cidades e seu papel na economia nacional, publicação do Comitê de Recursos Nacionais, Imprensa Oficial, 1937, Washington.

(8) A pesquisa inicialmente feita, em matéria de vida urbana, concentrou-se, como é natural, nos aglomerados étnicos, dentro das grandes cidades. Não obstante, os dados comparativos sôbre segregação aparecem com acentuada deficiência, em relação a períodos mais recentes. 
axiada. Quase tôdas as zonas urbanas, além de 10 ou 15 milhas do centrc, mantinham-se, em grande escala, independentes dêsse mesmo centro. Dentro de tais zonas, porém, o serviço de trens interurbanos foi aos poucos sendo capaz de funcionar com mais regularidade e, com o decurso do tempo, foi possível a um número cada vez maior de pessoas trabalhar na cidade e morar fora de seus limites formais. Êsses primeiros suburbanos habitavam em novas zonas residenciais localizadas a pequena distância das estações de estrada de ferro. Segundo disse HOYT, "A proporção que tais comunidades gradualmente se fundiam em aglomerações maiores, os mapas da área habitada das zonas metropolitanas de Nova York e Chicago mostravam longas projeções, que avançavam como se fôssem dedos, tendo entre si largos espaços vazios. Isso era o resultado das viagens mais rápidas que o trem suburbano oferecia, com vantagem sôbre os demais meios de transporte. (9)

TABELA 2 (*)

ESTRADAS DE FERRO E DE RODAGEM, DE 1900 A 1950

\begin{tabular}{|c|c|c|c|c|c|}
\hline & ANO & $\begin{array}{c}\text { Estradas } \\
\text { de } \\
\text { ferro } \\
\text { (extensão, } \\
\text { em milhas) }\end{array}$ & $\begin{array}{c}\text { Rodovias } \\
\text { calçadas } \\
\text { (milhas) }\end{array}$ & $\begin{array}{c}\text { Locomoti- } \\
\text { vas } \\
\text { (número) }\end{array}$ & $\begin{array}{c}\text { Veículos } \\
a \\
\text { motor } \\
\text { (número) }\end{array}$ \\
\hline 1950. & . . $\cdots$ & 223.779 & 1.714 .000 & 42.951 & 48.566 .984 \\
\hline 1940. & . $\ldots \ldots \ldots \ldots$ & 223.670 & 1.367 .000 & 44.333 & 32.035 .424 \\
\hline 1930. & $\cdot . \quad \ldots \ldots \ldots \ldots$ & 249.052 & 694.000 & 60.189 & 26.531 .999 \\
\hline 1920. &.$\quad \ldots \ldots \ldots \ldots$ & 252.845 & 369.000 & 68.942 & 9.239 .161 \\
\hline 1910. & . . $\quad \ldots \ldots \ldots \ldots$ & 240.293 & 204.000 & 60.019 & 468.500 \\
\hline 1900. &.$\quad \ldots \ldots \ldots \ldots \ldots$ & 193.348 & 128.500 & 37.663 & 8.000 \\
\hline
\end{tabular}

A importância das estradas de ferro, no princípio do corrente século, pode ser melhor apreciada à luz de um exame das estatísticas históricas constantes da Tabela 2. Ao despontar o século, o número de locomotivas era mais de quatro vêzes maior que o de veículos a motor, em funcionamento. Em 1910, havia mais quilômetros de trilhos de trem do que de estradas calçadas, mas após 1920, com o aumento significativo do número de veículos a motor, começou a decrescer o de locomotivas. Verifica-se o mesmo, aliás, quando se comparam os dois tipos de estrada.

A guerra de 1914 trouxe duas conseqüências particularmente significativas: primeiro, a migração do exterior, que havia suprido em grande parte as necessidades de mão-de-obra das cidades, foi pràticamente suprimida, enquanto as exigências da guerra forçavam os centros manufatureiros urbanos a aumentar sua produção. Para o serviço dos moinhos e das fábri-

(9) In A influência das estradas e dos transportes na estrutura e crescimento das cidades e no valor das terras urbanas, de HOYT, H., na publicação Estradas na vida nacional, editada por LABATUT, J., e LANE, W. H., p. 202, Imprensa da Universidade de Princeton, 1950.

(*) Font: - In "Estatísticas Históricas dos Estados Unidos, 1789-1945", do Bureau do Censo dos Estados Unidos, Imprensa Oficial, 1949, Washington as Tabelas K-29, K-34, K-175, K-182 e K-229; também na "Continuação, até 1952, das estatísticas históricas dos Estados Unidos, 1789-1945”, Imprensa Oficial, 1954, Washington, as mesmas tabelas . 
cas, era mister confiar na capacidade de atrair gente dos outros pontos do país e, pela primeira vez, as correntes migratórias começaram a incluir grande proporção de negros, oriundos principalmente do sul. (10)

O segundo ponto crucial decorrente da guerra foi o rápido aumento do número de veículos a motor. Carregadas até o extremo limite de sua capacidade, as estradas de ferro não podiam, de modo algum, conduzir tôda a carga que devia ser embarcada e os caminhões a motor, inicialmente usados apenas para transportes locais, dentro das cidades, foram logo postos em serviço, para condução das utilidades mais leves de um para outro ponto das zonas urbanas. Pôs-se em execução, em todos os níveis de govêrno, um amplo programa de melhoramento das rodovias e as estradas pavimentadas para tráfego pesado começaram a cruzar as áreas circunvizinhas dos grandes centros. Na realidade, o transporte em caminhões era subsidiado pelos fundos governamentais, pois as rodovias eram objeto de financiamento público. Além disso, aplicavam-se à produção de automóveis para uso particular alguns dos métodos aprendidos sob a pressão das egigências de guerra, no que concerne à necessidade de transporte em veículos a motor, e muitas das técnicas da moderna produção em massa - mais tarde adotada em quase todos os setores da economia - foram primeiro desenvolvidas na indústria automobilística.

Os anos que imediatamente se seguiram à primeira guerra mundial, embora caracterizados por algumas pequenas flutuações, assinalaram um período de expansão, em que enormes esforços foram feitos em matéria de produtividade industrial e, à proporção que crescia a produção nacional, ocorriam significativos aumentos nos salários. As técnicas de produção em massa e a mecanização crescente diminuíam as necessidades de mão-deobra da indústria e desde que tendência semelhante se manifestava no setor da agricultura, em conseqüência da introdução de maquinaria eletrificada, o excedente de população agrícola e industrial gradualmente mudava para as ocupações relacionadas com a distribuição de utilidades e serviços. (11)

De tais inovações tecnológicas decorreram alterações de sentido espaciaí. Ao mesmo tempo que essas transformações fundamentais se verificavam na economia nacional, o traçado físico da cidade grande e de sua área circunvizinha começava a sofrer radical modificação e a descentralização, que primeiro havia ocorrido apenas nos centros maiores, passou a ser, na década de 1920, um traço marcante do crescimento de muitas cidades de menos vulto, pois tanto a indústria como as populações se espalhavam, em conseqüência do desenvolvimento do veículo a motor. As estradas pavimentadas adaptavam-se, naturalmente, tanto à movimentação das pessoas quanto

(10) Assim começou um deslocamento do sul para o norte que até hoje prossegue, com a mesma intensidade. A maioria dos negros continua a mover-se diretamente para os núcleos citadinos, em lugar de fazê-lo para os círculos metropolitanos. As diferenciações raciais, nas várias correntes migratórias que interferem na questão da descentralização, não estão ainda devidamente estudadas.

(11) Para os efeitos da distinção inicial entre indústrias e ocupações "primárias", "secundárias" e "terciárias", veja-se a obra "Condições de progresso econômico", de CLARK, C., 2. ${ }^{a}$ edição, Macmillan Co., 1951, Londres. 
ao transporte das utilidades e a elaborada rêde de artérias principais e vias subsidiárias, que cercava as cidades grandes e de porte médio, permitia que muitos dos componentes funcionais da comunidade se emancipassem do centro. A maioria localizava-se em interseções das estradas e os subcentros urbanos apareciam em número cada vez maior, crescendo em ritmo mais acelerado que os centros principais. Novas construções surgiram, em volume considerável, na periferia das cidades grandes e médias. Na proporção em que as populações residenciais se aglomeravam em núcleos de razoável densidade, surgiam os estabelecimentos de comércio varejista e de serviços de tôda natureza, para pôr à disposição dos suburbanos o confôrto das cidades.

Contudo, com as crescentes facilidades de transporte, alguns dos subcentros maiores sofreram significativa transcrição, perdendo o alto grau de independência de que gozavam e caindo sob a dominadora influência da metrópole. Assim, por exemplo, muitos estabelecimentos do comércio de luxo deixaram de operar nos subcentros, ante a impossibilidade de competirem com a metrópole, agora fàcilmente acessível a um mercado mais amplo. Ao mesmo tempo, cada vez mais se aplicavam à distribuição das utilidades os princípios da produção em massa e começaram a surgir cadeias de unidades varejistas, negociando sobretudo com artigos domésticos. Tais organizações, subordinadas a uma chefia comum e dirigidas de um ponto qualquer, no centro da cidade, podiam beneficiar-se com a economia decorrente da padronização e das compras por ataçado. No mesmo período ocorreram importantes mudanças nas comunicações, com o desenvolvimento do rádio e do telefone. Tornou-se possível a comunicação instantânea com uma área maior e na mesma proporção reduziu-se a independência dos subcentros.

Enquanto isso acontecia, a indústria ficava cada vez mais em condições de localizar-se longe da cidade pròpriamente dita, porque a fôrça elétrica barata ia substituindo o vapor. (12) O telefone permitia que as facilidades de produção ficassem pela periferia, enquanto as funções de contrôle e de administração podiam permanecer no centro, além do que a posse de automóveis por um número cada vez maior de pessoas dava origem a uma fôrça de trabalho mais móvel. A indústria pesada, que tende a operar mais eficientemente em edifícios de um só andar e de vasta área, parecia mais particularmente atraída pelo baixo custo das terras no círculo adjacente às cidades, onde era menor a competição para outros usos.

Não obstante, nem todos os elementos da comunidade eram igualmente livres de participar dêsse movimento de dentro para fora e, na fase inicial da descentralização, muitas atividades ficavam tão prêsas ao centro como nos anos anteriores. O comércio dos artigos de luxo e os serviços de necessidade menos freqüente ficavam, de modo especial, obrigados a permanecer situados no centro, para continuarem acessíveis a um amplo mercado potencial. Também as funções de direção e administração pareciam apegar-se à localização central, talvez para que fôssem mais fáceis os contatos com outras unidades, ocupadas em comunicação, finanças e em mercados consumidores.

(12) Comitê de Recursos "Nacionais, op. cit. 
Seja como fôr, a depressão da década de 1930 parece ter acentuado a tendência no sentido de crescimento desigual, que s̊ manifestara em muitas regiões, nos anos anteriores. Tendo para oferecer reduzidas oportunidades de emprêgo, os centros citadinos viram seu crescimento descer a um nível baixo, o que representou perdas líquidas para muitas cidades. O aumento da população residencial do círculo metropolitano, embora reduzido em relação aos índices da década anterior, em muitos casos, inclinou-se a permanecer mais alto que o do centro e que o do país em conjunto. Não obstante haver poucas provas de um genuíno "movimento rumo ao campo", na década considerada, parece ter havido considerável acúmulo de migrantes em potencial, nas regiões adjacentes às cidades.

E' claro, porém, que dentro dos "círculos" metropolitanos, o crescimento rural excedeu o urbano, no período da depressão, e o desenvolvimetno das áreas rurais não incorporadas foi maior que o das pequenas regiões incorporadas. (13) A ameaça de guerra e as conseqüentes atividades armamentistas, nos últimos anos da década, impeliram, provàvelmente, as taxas de aumento de muitos núcleos citadinos, no lapso de tempo decorrido entre as décadas, a níveis mais altos do que aquêles que, em outras condições, seriam atingidos. Apesar do provável prosseguimento de forte migração no sentido da cidade pròpriamente dita, nos últimos anos da década de 30 , o crescimento dos círculos mostrou sempre tendência a exceder o dos núcleos metropolitanos das cidades, mesmo as menores. Maioria bem considerável das cidades de cinqüenta mil habitantes e mais mostrava então um quadro de relativa descentralização, antes visto apenas em redor das cidades maiores. (14)

Finalmente, a mais recente década entre-censo (1940-1950) testemunhou uma difusão progressiva dos padrões que se haviam configurado anos antes, nas cidades maiores. Não apenas os centros metropolitanos, mas também os satélites maiores, dentro da órbita metropolitana, sofrem um processo de descentralização. O crescimento das áreas rurais e não incorporadas continua a suplantar o das urbanas e incorporadas. A forma física da área metropolitana, que exibia o padrão axiado, está como que enchendo e a região assemelha-se a uma grande massa amorfa, embora ainda seja possível discernir-se o antigo contôrno estelar. Mais importante que isso, os limites funcionais da área metropolitana, tal como o indica a mudança das altas taxas de crescimento para o movimento de dentro para fora, parece haverem também variado, de um círculo aproximado de dez milhas para outro, de entre vinte a vinte e cinco milhas de diâmetro. (15)

No decurso dêsses cinqüenta anos de transição, há certo número de circunstâncias, de caráter estrutural e funcional, que, ao que parece, tem

(13) A antiga (1940) definição de "urbano" e "rural", aqui usada, tende, de modo acentuado, a superestimar o componente rural, pois muita gente classificada como "rural" é, na realidade, membro do grupo urbano, do ponto de vista de qualquer definição funcional razoável.

(14) Descentralização metropolitana - Estudo sôbre crescimnto desigual, BoGuE, D. J., Fundação Scripps para pesquisa de problemas populacionais, 1950, Oxford, Ohio.

(15) Aspectos da América Metropolitana - Descentralização, desde 1920, HAwLEy, A. H., Imprensa Livre, 1956, Glencoe. 
estado relacionado ao crescimento centrífugo e delas a mais importante é simplesmente o tamanho da população. Na realidade, em sua maioria os outros fatôres associados ao crescimento centrífugo estão, êles próprios, associados ao tamanho da metrópole, embora a localização regional pareça, também, ser fator de real significação. Contudo, outras variáveis relacionadas a êsses dois fatôres - tamanho e localização regional - mostram, com a descentralização, uma associação que perdura, ainda que os dois citados fatôres estejam controlados.

Além das variáveis primárias, pesquisas recentes mostram que as áreas em que a descentralização se manifestou muito cedo e prosseguiu em ritmo acelerado tendem a exibir núcleos citadinos densamente povoados, de desenvolvimento lento, no último meio século. Na maioria dos casos, tais cidades são velhas cidades costeiras, em cuja área as atividades manufatureiras foram sendo descentralizadas em todo o decurso do período considerado. (16) Tôdas essas conclusões, quando tomadas em conjunto, mostram a importância do que poderíamos chamar a "maturidade" das áreas metropolitanas . Aquelas que mostraram, desde cedo e mais marcadamente, as provas da descentralização, parece terem alcançado um estado avançado de maturidade, que meramente se reflete nas características estruturais e funcionais aqui enumeradas. Num sentido lato, a descentralização é um índice da maturidade das áreas metropolitanas.

\section{ALGUMAS CONCLUSÕES DA PESQUISA}

Somando-se às necessidades de pesquisa a que de início fizemos referência, vários outros problemas apresentam-se para um exame prático. Tôda uma ordem de problemas de pesquisa pode ser resumida sob a epígrafe das causas do crescimento desigual dentro das áreas metropolitanas. Além da contribuição relativa do crescimento natural e da migração líquida, temos que saber as origens dos migrantes, por tipo de área e de função. Outra legião de questões empíricas surge quando consideramos a composição demográfica e funcional das várias partes da área metropolitana e as correntes migratórias que fluem entre elas. Importantes como o sejam tais problemas apenas se relacionam, porém, com a população residencial das áreas metropolitanas. (17)

(16) HAWLEY, op. cit. . Em cada exemplo, a direção da associação entre uma determinada variável e o crescimento centrífugo tende a ser a mesma encontrada entre a variável em questão e o tamanho de metrópole. A direção dessa relação continua a mesma, embora reduzida em extensão, quando se consideram os tamanhos de classe. Não obstante não se encontrar nenhuma área isolada tendo tôdas as características, as mesmas tendem a associar-se umas com as outras.

(17) ALBERT J. Reiss Jr. sugeriu, recentemente, vários excelentes tópicos para pesquisa nessas áreas (Veja-se Problemas de pesquisa de redistribuição de populações metropolitanas, in "Revista Americana de Sociologia", n. ${ }^{\circ}$ XXI, pp. 571-577, outubro, 1956). Alguns dêsses tópicos, porém, são de orientação estatística. Outro estudo apreciável sôbre o assunto contém-se no trabalho de HENRY S. SHYROCK JR., Redistribuição popu lacional nas áreas metropolitanas - Avaliação da pesquisa, in "Fôrças Sociais", n. ' XXXV, pp. 154-159, dezembro, 1956. 
Além do interêsse pela redistribuição de população residencial, é claro que uma descrição completa da evolução organizacional da área metropolitana deve cuidar das demais unidades sociológicas que compõem a comunidade como um todo. Parece que tôdas as atividades urbanas típicas as funções chamadas "secundárias" e "terciárias", que concernem à fabricação, à distribuição e ao contrôle (18) - têm ficado sujeitas, de algum modo, às mesmas fôrças de descentralização que, de forma tão dramática, alteraram o padrão da distribuição residencial, dentro das áreas locais. A redução do atrito provocado pela distância tem tido efeitos notáveis, em quase tôdas as esferas da vida.

Quanto às atividades secundárias (do tipo manufatureiro), é fora de dúvida que estão cada vez mais livres para se localizarem às margens da comunidade. Como salienta BOGUE, "os economistas e os industriais descobriram que, sob as modernas condições de transporte, não é mais necessário para as grandes indústrias ficarem situadas dentro dos limites do núcleo citadino. Há uma larga zona, provàvelmente de várias milhas de diâmetro, adequada do ponto de vista da localização". (19) Atividades terciárias (comércio, serviços de diversas naturezas, etc.) são provàvelmente afetadas de modo semelhante pelas modificações sofridas pelo conceito de conveniente localização, mas foram menos cuidadosamente estudadas. A descentralização de funções como o comércio atacadista, os grandes armazéns e a distribuição é assunto que merece pesquisas mais detidas. Tais atividades têm sido tradicionalmente encaradas como de orientação para o centro, mas progressos recentes em matéria de organização metropolitana conduzem a uma reconsideração dêsse julgamento. Transporte mais rápido e mais freqüente, por exemplo, pode ter contribuído para reduzir a necessidade de localização central dos grandes armazéns. O problema de condução das cargas tornou-se uma operação muito mais flexível, depois do desenvolvimento do caminhão a motor e, aparentemente, uma grande parte da função de armazenamento desenrola-se ao longo das estradas sem que haja necessidade da manutenção de grandes estoques e da pronta preparação de inventários.

Muitas das funções administrativas, igualmente, vão ficando cada vez mais em condições de deixar o centro e de se localizar na periferia da comunidade metropolitana. Os escritórios centrais das grandes companhias de seguros, por exemplo, cujos contatos principais são com agentes espalhados por todo o país, podém ser tomados como tipo representativo da administração que pode ser feita tão eficientemente do círculo quanto do centro da cidade. Já o contrôle e a direção de outras indústrias, nas quais são necessários freqüentes contratos como advogados, corretores, imprensa, agências de publicidade e clientes situados fora da cidade, podem continuar exigindo localização central. Ulteriores pesquisas deveriam definir os demais órgãos com que determinada função exige aproximação mais constante, tanto diretamente como através de comunicações, além das indicações sôbre espaço,

(18) ClaRK, op. cit.

(19) Necessidade da pesquisa urbana e metropolitana, editada por BOGUE, D.J Fundação Scripps para pesquisa de problemas populacionais, p. 40, 1953, Oxford, Ohio. 
em quantidade e espécie. Tais dados forneceriam esclarecimentos valiosos sôbre o grau de descentralização a esperar-se, entre várias atividades.

Ainda estão para ser exploradas as diferenças funcionais entre zonas suburbanas e satélites e um conhecimento minucioso de seus aspectos é necessário para que se possa fazer a descrição completa da organização social e econômica de uma comunidade em expansão. (20) Mais ainda, há muito que aprender sôbre as tendências de crescimento de tipos diferentes de subnúcleos, no círculo metropolitano. Os satélites que se caracterizam como zonas empregadoras, por exemplo, mostram padrões de crescimento acentuadamente diferentes dos subúrbios apenas residenciais. (21) O desenvolvimento de zonas mais especializadas, incluindo centros educacionais e recreativos, pode exibir padrões divergentes, de acôrdo com o papel altamente especializado que as mesmas desempenham no conjunto da área metropolitana.

As tendências do aumento de população, dentro do núcleo citadino pròpriamente dito, merecem mais detido exame. A congestão física do centro tem sido, freqüentemente, apontada como uma das causas da descentralização. A maioria das grandes cidades dispõe de vasta extensão de terra habitável que permanece devoluta, (22) mas da qual uma parte considerável constitui-se de pequenas propriedades retidas para especulação, forçando os preços além dos limites que permitem o desenvolvimento de uma zona residencial.

Uma descrição mais acurada do papel desempenhado pelo congestionamento pode, à mesmo tempo, ser obtida se dispensarmos atenção ao problema do tráfego, êle próprio conseqüência da separação dos usos da terra, vistos na descentralização residencial. (23) As densidades do tráfego exercem, provàvelmente, influência maior que as da população residencial, estas estudadas com muito maior frequêencia. O acúmulo diário de grandes massas de povo e veículos, nas áreas centrais, pode tolher de tal modo o movimento que o centro acaba perdendo sua posição, tradicional e favorável, de ponto mais acessível de tôda a área metropolitana.

Uma área matropolitana estreitamente definida oferece muitas possibilidades para comparações de caráter cultural. Foram feitos vários estudos sôbre a viagem diária para o trabalho, tanto na Europa como nos Estados Unidos. (24) Em nosso país, tais estudos basearam-se, sobretudo, em dado

(20) Veja-se o estudo Uma tipologia das comunidades suburbanas - $O$ distrito de Chicago, em 1940, de DoRnBusch, S. M., (in Relatórios sôbre análises urbanas, n. ${ }^{\circ}$ 10, Inventário da comunidade de Chicago, Chicago maio, 1952) e, de Leo F. SchnorE, As funções dos subúrbios metropolitanos, no n. ${ }^{\circ} \mathrm{LXI}$, de março de 1956, do "Jornal Americano de Sociologia", pp. 453-458.

(21) O crescimento dos subúrbios metropolitanos, ScHNoRE, L. F., in "Revista Americana de Sociologia, n. ${ }^{\circ}$ XXII, pp. 165-173, abril, 1957.

(22) Usos da terra nas cidades americanas, de BARTHOLOMEw, H., Imprensa da Universidade de Harvard, 1955, Cambridge.

(23) População urbana diária - Campo para uma análise demográfico-ecológica, de FOLEY, D. L., in Fôrças Sociais, n. ${ }^{\circ}$ XXXII, pp. 323-330, maio, 1954.

(24) Idem, idem, e $A$ viagem para o trabalho, de LIEPMANN, K.K., Imprensa da Univ. de Oxford, 1944, New York. 
secundários, resultantes de pesquisas sôbre tráfego e, sendo limitados a áreas que constituíam sérios problemas de tráfego, representam as investigações americanas, provàvelmente, uma amostra pouco isenta das áreas metropolitanas encaradas em conjunto. Muitos dos estudos europeus, contudo, apoiaram-se em material obtido nos recenseamentos, pois os censos da maioria das nações européias incluem pelo menos uma questão, concernente ao lugar de atividade dos componentes da fôrça assalariada de trabalho. (25) E' êste um dos raros casos em que o censo americano perde, em matéria de coleta de dados, para outros países do mundo.

As informações colhidas sôbre os lugares de trabalho, nos futuros recenseamentos, permitiriam uma configuração muito mais completa da organização funcional de tôda a área metropolitana; as circulações e baldeações diárias - centrífugas, centrípetas e laterais - entre as várias subpartes da área poderiam, então, ser minuciosamente determinadas. (26)

Certas observações, feitas prèviamente neste trabalho, levam à conclusão de que a moradia nos locais afastados fica restrita aos grupos de maiores rendimentos. Não obstante, o rápido aumento do número dos possuidores de automóvel, em todas as camadas de nossa sociedade, tornou os subúrbios e as regiões satélites, assim como as zonas não incorporadas do círculo metropolitano, acessíveis aos que possuem recursos módicos e mesmo a alguma pessoas de baixos rendimentos. Onde quer que haja lugares em que não prevaleça regulamentação sôbre zoneamento, podem construir-se casas baratas, em terras igualmente baratas. Pesquisas esparsas demonstram que o padrão europeu de trabalho parcial em granjas e sítios, por operários dos centros urbanos, pode vir a ser estabelecido nas vizinhanças de muitas cidades industriais americanas, especialmente daquelas em que o trabalho nas fábricas é periódico. (27) O sistema de partilhar os ônus da viagem, usado entre os trabalhadores urbanos que habitam o círculo, constitui ainda outro recurso que permite a localização residencial periférica àqueles que, de outro modo, não poderiam arcar com a despesa do alto custo do transporte para o centro. (28).

(25) FOLEY, op. cit...

(26) O rápido progresso observado nas técnicas de amostra estatística deveria permitir êsse valioso aperfeiçoamento, no censo de 1960 . Os problemas técnicos podem ser resolvidos pela experimentação com métodos alternativos, no inquérito sôbre população atual, bem como em alguns recenseamentos especiais, em Estados e Municipalidades, antes da aplicação ao recenseamento federal do próximo decênio.

(27) "Estudos de suburbanização em Connecticut, - N.० 2: Norwich, uma árę industrial parte do tempo ocupado em agricultura", estudo de WHETTEN, N. L. . e FIELD, R. F., in "Boletim n. ${ }^{\circ} 226$, da Estação Experimental de Agricultura, do Colégio Estadual de Connecticut, 1938, Storrs; Zonas satélites, de GoRDON, W. R., in "Boletim n. ${ }^{\circ} 282$, da Estação Experimental de Agricultura, do Colégio Estadual de Rhode Island, 1942, Kingston; Aspectos sociais do planejamento do uso da terra nas zonas entre a cidade e o campo, de FIERY, W., in Boletim n. ${ }^{\circ}$ 339, da Estação Experimental de Agricultura do Colégio Estadual de Michigan, 1946, East Lansing; Moradia e viagem para o trabalho, de BEYER, G. H., in Boletim n. ${ }^{\circ}$ 877, da Estação Experimental de Agricultura, da Universidade Cornell, 1951, Ithaca.

(28) A separação entre casa e trabalho, um problema de ecologia humana, de SCHNORE, L. F., in "Fôrças Sociais", n. ${ }^{\circ}$ XXXII, de maio, 1954, pp. 336-345. A chamada "fôrça marginal de trabalho" parece localizar-se, realmente, à margem das cidades 
De um modo mais geral, as tendências verificadas em matéria de habitação tiveram papel importante no desenvolvimento de todo êsse quadro, mas êsse é um caso em que a pesquisa é extremamente deficiente. Com a passagem dos anos, as técnicas da produção em massa têm sido adaptadas à construção de casas e precisamos conhecer os fatôres causais de natureza dinâmica que influem no aparecimento das diferenças de zona, nas construções de vários tipos, dentro da comunidade metropolitana. Esse conhecimento clarificaria o problema da redistribuição da população residencial, bem como de outros componentes funcionais, como estabelecimentos industriais e comerciais. (29).

A êsse respeito, poder-se-ia orientar parte da pesquisa no sentido de uma definição mais cuidadosa de algumas das diferenças no nível sócio-econômico, entre as regiões suburbanas e satélites, dentro do círculo metropolitano. Os dados sôbre aluguéis e sôbre rendimentos são hoje disponíveis pelo menos em relação às zonas maiores e já incorporadas do círculo adjacente e podem ser fàcilmente suplementados por estatísticas sôbre educação e composição étnica e ocupacional. Muitos observadores apontam a emergência de rígida segregação nos subúrbios, ao longo de linhas sociais e econômicas. Diz-se, na verdade, que a construção em massa de casas suburbanas atrai pessoas de nível semelhante, (30) compulsão econômica no sentido de uma separação que parece continuar com o zoneamento. Quanto ao fato de serem tais tendências mais coercitivas, contudo, do que as fôrças que de há muito contribuíram para a segregação dentro da cidade, isso constitui matéria para ulteriores pesquisas.

A presente discussão valeu-se do conceito de área metropolitana típica recentemente desenvolvido nos estudos demográficos. Sempre que se usa, na pesquisa, um instrumento de aferição estatística como êsse, é fora de dúvida que êsse uso é um teste de sua validade. Há indícios de que a área metropolitana típica inclui apenas a zona de mais rápido crescimento nos últimọ anos, mas tanto BOGUE como HAWLEY têm mostrado que a influência da metrópole se reflete nas taxas de aumento de áreas muitas milhas para fora da zona residencial. Além dessa zona de intercâmbio primário, existe, naturalmente, um vasto interior, onde a integração com o centro se faz através de contatos indiretos. Dêsse modo, a pesquisa não pode ficar limitada apenas à área metropolitana típica, embora a área de contato direto com o centro pareça estar bem demarcada pela definição. Seja como fôr, a utilidade dessas áreas como unidades de comparação é valorizada pela gran-

industriais, o que leva à conclusão de que a "franja rural e urbana" é suscetível de identificação tanto em têrmos funcionais (ocupacionais) quanto de área. Esta última concepção, aliás, pode em muitos casos conduzir a conclusões extremamente errôneas.

(29) Estrutura da área metropolitana e crescimento, segundo as estatísticas de licenças para construções, de NEwMAN, D. K., in Negócios, n. ${ }^{\circ}$ IV, de novembro, 1956, pp. 1-7. Dentro das áreas metropolitanas, constrói-se, no círculo, de forma extremamente rápida. Embora os dados de NEWMAN se refiram apenas a um número reduzido de áreas, sòmente 8 , dentre as 168 áreas metropolitanas típicas atualmente reconhecidas, não apresentam proporção mais alta de novas habitações no círculo e sim no núcleo citadino.

(30) Diferenciação nas áreas metropolitanas, de KISH, L.. in "Revista Americana de Sociologia", n. ${ }^{\circ}$ XIX, de agôsto, 1954, pp. 388-398. 
de soma de dados recolhidos numa base de condado, por outros serviços oficiais e particulares. A aplicação mais ampla de tais dados permitirá, pelo menos, que se dê a uma série de problemas atuais uma tentativa de resposta.

Muitos problemas de administração e planejamento aparecem graças ao fato de desconhecermos, em minúcia, a mudança de forma sofrida pela comunidade. O fornecimento de descrições exatas da estrutura da comunidade cabe à pesquisa sociológica, mas a tarefa é, em si, muito mais complexa. Se devemos solver a multidão de problemas práticos que se projeta tão ràpidamente no rastro da descentralização, teremos que reunir fatos cada vez mais numerosos. E, mais importante ainda, teremos que dispor de esquemas conceituais, com que interpretar êsses fatos.

As questões levantadas neste estudo deixam clara a convicção de que temos necessidade de uma completa teoria, que sumarize tanto os aspectos estruturais como os funcionais, de tôdas as unidades constitutivas da comunidade. Mais ainda, tal teoria deverá ser capaz de originar hipóteses testáveis, medindo não só relações estáticas, mas também dinâmicas, entre as variáveis, como o progresso tecnológico, a reutilização da terra, a segregação, o crescimento das populações e a redistribuição - todos êsses têrmos querendo significar processos. Qualquer interpretação conceitual sadia deverá ser expressa em têrmos dinâmicos como os que mencionamos, isso porque se faltarem outras razões - a comunidade metropolitana está continuamente em mudança.

A criação de uma tal teoria não será mero exercício intelectual, pois como assinalou recentemente um demógrafo:

"uma das razões de tão fortes discordâncias e de tão divergentes conclusões a propósito da chamada "descentralização" está em que os especialistas em matéria de população urbana e de ecologia humana falharam na tarefa de formar uma teoria de crescimento urbano válida para nossa época. Talvez tenhamos estado preocupados, sobretudo, com o aperfeiçoamento de uma teoria estática da estrutura das cidades... Nossos estudos nessa matéria devem ser acompanhados de um rigoroso programa de pesquisas sôbre crescimento e mudança. A pesquisa, no que diz respeito a urbanismo e a metropolitanismo, deveria ter aspectos tanto dinâmicos quanto estáticos. (31)

Não podemos senão concordar com tão ambiciosos objetivos, esperando que os tópicos discutidos neste trabalho possam contribuir para que sejam os mesmos alcançados.

(31) Necessidades da pesquisa urbana e metropolitana, de Bogue, p. 38. Universidade da Califórnia, Berkeley. 